\title{
Effect of an external applied potential on the photocatalytic properties of manganese-doped titanium dioxide
}

\author{
Gracien Bakambo Ekoko, Joseph Kanza-Kanza Lobo, Omer Muamba Mvele*, \\ Jérémie Lunguya Muswema*, Jean-Félix Senga Yamambe \\ Department of Chemistry, University of Kinshasa, P. O. Box 190, Kinshasa XI, Democratic Republic of Congo
}

Email address:

omer.mvele@unikin.ac.cd (O. M. Mvele), jeremie.muswem@unikin.ac.cd (J. L. Muswema)

\section{To cite this article:}

Gracien Bakambo Ekoko, Joseph Kanza-Kanza Lobo, Omer Muamba Mvele, Jérémie Lunguya Muswema, Jean-Félix Senga Yamambe. Effect of an External Applied Potential on the Photocatalytic Properties of Manganese-Doped Titanium Dioxide. American Journal of Physical Chemistry. Vol. 3, No. 4, 2014, pp. 41-46. doi: 10.11648/j.ajpc.20140304.11

\begin{abstract}
The electrochemical anodic oxidation method was used to prepare thin films of titanium dioxide $\left(\mathrm{TiO}_{2}\right)$ semiconductors (undoped and doped with $\mathrm{Mn}$ ). These films were used to test the oxidation of methanol $\left(\mathrm{CH}_{3} \mathrm{OH}\right)$, the degree of which was quantified by measuring the current density produced as a function of an applied potential between 0.5 $\mathrm{V}$ and $5.0 \mathrm{~V}$. The value of the potential to be applied in order to prevent fast electron-hole recombination was determined. The observed phenomenon is explained by considering the wave nature of the electron.
\end{abstract}

Keywords: Anodic Oxidation, $\mathrm{TiO}_{2}$, Mn-Doped $\mathrm{TiO}_{2}$, Applied Bias, Tunnelling Process

\section{Introduction}

The remarkable photocatalytic properties of nanosized $\mathrm{TiO}_{2}$ semiconductor particles have, in the recent past years, prompted an intense research work which still continues with unabated interest [1,2]. It is well known that $\mathrm{TiO}_{2}$ (anatase) has a band gap of $3.2 \mathrm{eV}$. It can, therefore, be excited upon irradiation with ultraviolet light (UV) at 365 $\mathrm{nm}$. This excitation leads to the promotion of electrons $\left(e^{-}\right)$ from the valence band (VB) to the conduction band (CB) leaving behind holes $\left(h^{+}\right)$in the VB as shown in Eq. 1:

$$
\mathrm{TiO}_{2} \stackrel{h v}{\longrightarrow} \mathrm{TiO}_{2}\left(h_{V B}^{+} \ldots \ldots . . e_{C B}^{-}\right)
$$

The produced charge carriers $\left(h^{+}\right.$and $\left.e^{-}\right)$can recombine within $10^{-9} \mathrm{~s}$, generating heat. This recombination substantially reduces the photocatalytic ability of $\mathrm{TiO}_{2}$ to oxidize organic pollutants. It has been reported that the probability of charge carriers' recombination diminishes as the grain size of $\mathrm{TiO}_{2}$ decreases, what should result in an improvement of the photocatalytic properties [2].

Fujishima and Honda [3] were the first ones to use a single crystalline $\mathrm{TiO}_{2}$ photoanode for electrocatalytic decomposition of water under the influence of an external applied anodic potential. The application of such an anodic bias was found to increase the photocatalytic efficiency of $\mathrm{TiO}_{2}$ for degrading undesirable pollutants in aqueous solution.

The electron transport in nano-crystalline $\mathrm{TiO}_{2}$ electrode occurs via diffusion and is not potential dependent, while the Fermi energy level of such a semiconductor is potential dependent [2]. Therefore, the application of a positive potential could be expected to lower the Fermi energy level of the semiconductor. This would increase the efficiency of electron removal from the illuminated semiconductor film and consequently improve quantum efficiencies by limiting recombination of charge carriers. The role of an external potential is then to drive away the photogenerated electrons and so reduce the electron-hole recombination. The photogenerated hole acts as an oxidizing species of the organic pollutants present in the aqueous solution [4].

Some researchers had studied the synergic effect on the oxidation of organic pollutants under higher-potential applied bias (up to $30 \mathrm{~V}$ ). Their results showed that the oxidation was due both to the electrochemical and the photocatalytic oxidation in the presence of $\mathrm{TiO}_{2}$ [5-9].

It is now known that incorporation of a transition metal 
into the lattice of $\mathrm{TiO}_{2}$ inhibits the recombination of charge carriers in the semiconductor. The enhancement in activity that results from it can be explained in terms of a photoelectrochemical mechanism in which the electrons generated upon illumination of $\mathrm{TiO}_{2}$ by UV light are drawn to the loaded metal cations $\left(\mathrm{M}^{\mathrm{n}+}\right)$, while holes remain in the VB of the semiconductor [10-12].

The aim of the present work was to determine, experimentally, the value of the external applied bias that, by preventing electron-hole recombination, would positively affect the photocatalytic properties of $\mathrm{TiO}_{2}$ in the oxidation of organics. The efficiency of the method is tested with $\mathrm{CH}_{3} \mathrm{OH}$ which is chosen as pollutant model.

\section{Experimental}

As illustrated in Scheme 1, an electrochemical method comprising three steps was designed to prepare multinanoporous particles of titanium dioxide, in anatase structure, doped with manganese atoms. The titanium sheet was the starting material while the anodic oxidation and the electrodeposition were the starting point for all the synthetic methods.

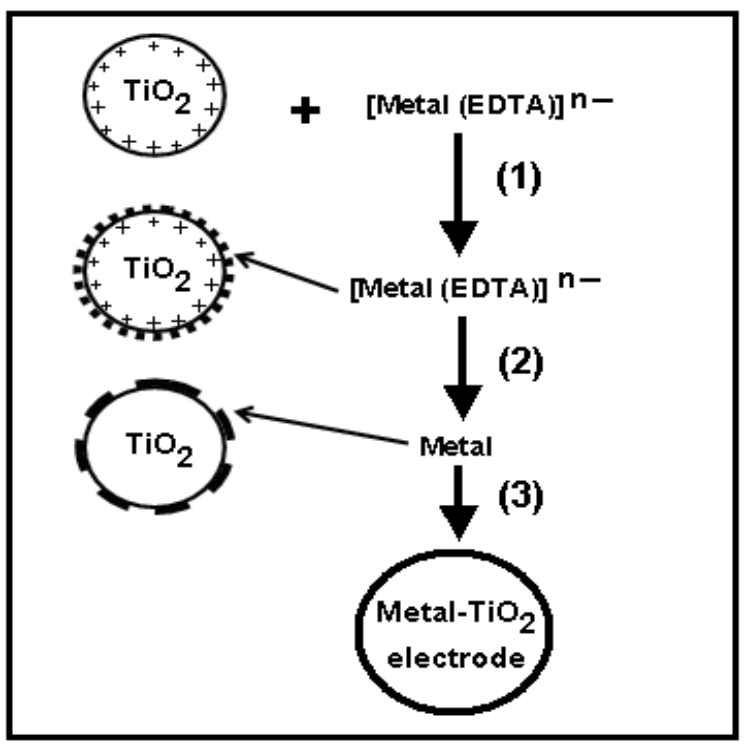

Scheme 1. The three-step electrochemical method used for the production of transition metals doped-TiO $\mathrm{O}_{2}$ electrodes.

Step 1: The first step consisted of anodization, at ambient temperature, of the titanium film in oxalic acid solution $\left(0.8\right.$ mol.dm $\left.{ }^{-3}\right)$, at high current density $\left(90-100 \mathrm{~mA} . \mathrm{cm}^{-2}\right)$ and low voltage $(60 \mathrm{~V})$ for $3 \mathrm{~min}$. This process leads to the formation of a conductive porous coating layer of $\mathrm{TiO}_{2}$ over the entire surface of the titanium film. This film is the preanodized $\mathrm{TiO}_{2}$ [13-17].

Step 2: In the second step, atoms of manganese (Mn) were incorporated into the conductive pores of the preanodized $\mathrm{TiO}_{2}$ through electrodeposition, using $\mathrm{MnSO}_{4}(12$ g. $\mathrm{dm}^{-3}$ ) to provide a metal-doping agent in ionic form [1-5]. The electrodeposition was carried out under a high current density of about $75 \mathrm{~mA} . \mathrm{cm}^{-2}$ to $90 \mathrm{~mA} \cdot \mathrm{cm}^{-2}$. For this purpose, an output voltage statically controlled alternative electric power source and a thermostatically controlled water bath were used. During the electrodeposition process, the bath was kept at $40{ }^{\circ} \mathrm{C}$ and the $\mathrm{pH}$ at 2.0.

The high current was applied to enhance the adhesion of manganese atoms into the coating layer [18-20]. The $\mathrm{pH}$ was set at 2.0 because at higher values, the stability of the bath decreased and this could cause precipitation or incorporation of non-adherent manganese hydroxides in the metal coating. Boric acid $\left(10 \mathrm{~g} . \mathrm{dm}^{-3}\right)$ was also added to the solution to increase its conductivity (i.e. to lessen high current density burning) and thus to prevent precipitation of the manganese hydroxides. Not using boric acid may cause inefficient and poor adhesion of manganese atoms on the pre-anodized $\mathrm{TiO}_{2} . \mathrm{Na}_{2}$ (EDTA) $\left(0.02 \mathrm{~mol} . \mathrm{dm}^{-3}\right)$ was added as a chelating agent to increase the solubility of the metal through anionic complex formation with $\mathrm{Mn}$ (II) ions. The anionic complexes formed were electrostatically bound to the positive surface of $\mathrm{TiO}_{2}$. The electrodeposition time varied from $4.0 \mathrm{~min}$ to $30 \mathrm{~min}$.

Step 3: At this stage, re-anodizing was performed at room temperature for $5 \mathrm{~min}$, by direct current $(\mathrm{dc})$ in sulfuric acid solution $\left(1.0 \mathrm{~mol} . \mathrm{dm}^{-3}\right)$, at high voltage (130 $\mathrm{V})$, with a current density of about $15 \mathrm{~mA} \cdot \mathrm{cm}^{-2}$ to 20 $\mathrm{mA} . \mathrm{cm}^{-2}$. The cathode was made of graphite. Nanoporous films consisting of $\mathrm{TiO}_{2}$ particles doped with atoms of manganese were then produced. The films were immediately rinsed with distilled water to remove byproducts, then dried in air and finally characterized. Energy Dispersive X-ray Spectroscopy (EDS) was used to investigate the elementary chemical composition of the films obtained.

A Raman scattering spectrum was recorded at room temperature using a Spex 1403 Laser Raman scattering spectrometer with the aim of determining the $\mathrm{TiO}_{2}$ structure in our study. The laser power was kept low in order to avoid undesired heating effects of the samples.

The effect of a potential bias on the oxidation of $\mathrm{CH}_{3} \mathrm{OH}$ in aqueous solution was investigated using $\mathrm{TiO}_{2}$ and manganese-doped $\mathrm{TiO}_{2}$ electrodes. The oxidation of $\mathrm{CH}_{3} \mathrm{OH}$ was quantified via current density measurements using $\mathrm{TiO}_{2}$ as working electrode and a circular electrode (made of graphite) as a counter electrode. For this purpose, the oxidation under UV light (at $365 \mathrm{~nm}$ ) of $\mathrm{CH}_{3} \mathrm{OH} 0.2$ mol. $\mathrm{dm}^{-3}$ in aqueous solutions was investigated. Sodium sulphate $\left(\mathrm{Na}_{2} \mathrm{SO}_{4} 0.3 \mathrm{~mol} . \mathrm{dm}^{-3}\right)$ was used as supporting electrolyte because $\mathrm{Na}_{2} \mathrm{SO}_{4}$ has high conductivity, which can be translated into little or no ohmic resistance between the reference electrode and the working electrode, so that the measured current is limited by $\mathrm{CH}_{3} \mathrm{OH}$ solution diffusion at the $\mathrm{TiO}_{2}$ surface $[19,20]$. The photoanode $\mathrm{TiO}_{2}$ (surface area $95 \mathrm{~cm}^{2}$ ) and the circular electrode were immersed in the photoreactor containing the $\mathrm{CH}_{3} \mathrm{OH}$ solution. The applied voltage was varied from $0.5 \mathrm{~V}$ to 5.0 $\mathrm{V}$, and the changes in current density were recorded as a function of the applied potential. 


\section{Results and Discussion}

Table 1. Manganese contents (in atom percent) of the $\mathrm{TiO}_{2}$ electrodes as a function of the electrodeposition time.

\begin{tabular}{ll}
\hline Electrodeposition time (min) & $\begin{array}{l}\text { Mn contents in Mn-doped } \mathrm{TiO}_{2} \\
\text { electrodes (at.\%) }\end{array}$ \\
\hline 4.0 & $0.31 \pm 0.02$ \\
6.0 & $0.50 \pm 0.01$ \\
8.0 & $1.03 \pm 0.01$ \\
10.0 & $1.12 \pm 0.03$ \\
13.0 & $1.71 \pm 0.02$ \\
20.0 & $1.93 \pm 0.02$ \\
30.0 & $2.40 \pm 0.03$ \\
\hline
\end{tabular}

The results on the elementary chemical composition of the films are presented in Table 1. Each value of the manganese contents given in the table is an average of three measurements of manganese contents made at three different points of the electrode under study.

Fig. 1 shows the X-ray diffraction patterns of $\mathrm{Mn}-\mathrm{TiO}_{2}$ (with 1.03 at.\% and 2.40 at.\% of $\mathrm{Mn}$ as dopant), and of undoped $\mathrm{TiO}_{2}$. From Fig. 1, it can be seen that an increase in $\mathrm{Mn}$ contents up to 2.40 at.\% leads to the formation of $\mathrm{MnO}_{2}$ while at 1.03 at.\% only one phase of $\mathrm{TiO}_{2}$ (anatase) is observed. No dopant related peaks were observed by $\mathrm{X}$ ray diffraction analysis. This suggests that there is no metal aggregation in amounts large enough to be detected by $\mathrm{X}$ ray diffraction [1].

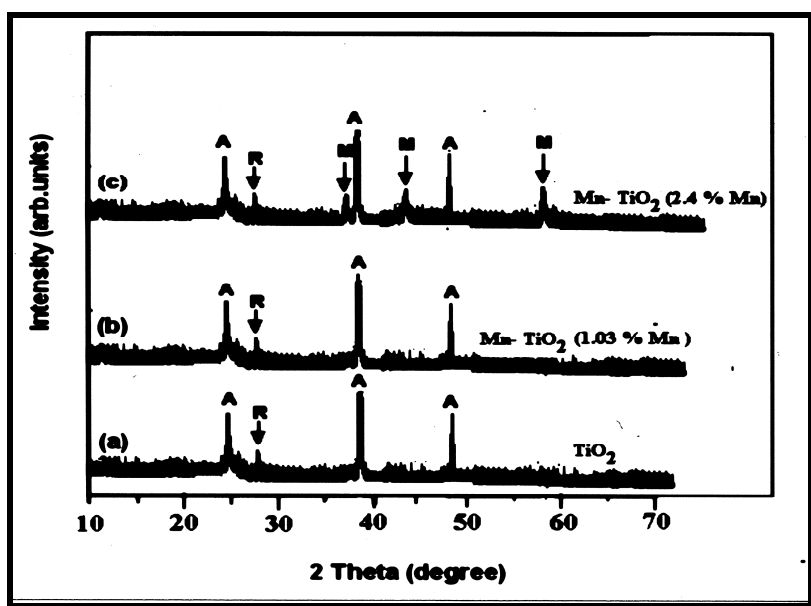

Fig 1. X-ray patterns of (a) undoped $\mathrm{TiO}_{2}$, (b) $\mathrm{Mn}$-doped $\mathrm{TiO}_{2}(\mathrm{Mn}: 1.03$ at.\%), and (c): Mn-doped $\mathrm{TiO}_{2}$ (Mn: 2.40 at. \%). The various Bragg peaks are followed by $A$ : anatase, $\mathrm{R}$ : rutile, $\mathrm{M}: \mathrm{MnO}_{2}$. The results were obtained using $C u K_{\alpha}$ radiation $(\lambda=1.54178 \AA)$.

Fig. 2 presents the Raman scattering spectrum of the prepared undoped $\mathrm{TiO}_{2}$ and $\mathrm{Mn}$-doped $\mathrm{TiO}_{2}$. The Raman peaks are located around $408.71 \mathrm{~cm}^{-1}, 511.9 \mathrm{~cm}^{-1}$, and $642.1 \mathrm{~cm}^{-1}$, corresponding to $\mathrm{B}_{1 \mathrm{~g}}, \mathrm{~A}_{1 \mathrm{~g}}$ or $\mathrm{B}_{2 \mathrm{~g}}$, and $\mathrm{E}_{\mathrm{g}}$ modes of $\mathrm{TiO}_{2}$ anatase structure, respectively $[21,22]$.

The additional peak at $448.612 \mathrm{~cm}^{-1}$ is attributable to the rutile phase of $\mathrm{TiO}_{2}$. This result is consistent with the analysis from X-ray diffraction spectrum of the prepared $\mathrm{TiO}_{2}$ and $\mathrm{Mn}$-doped $\mathrm{TiO}_{2}(\mathrm{Mn}: 1.03$ at.\%).

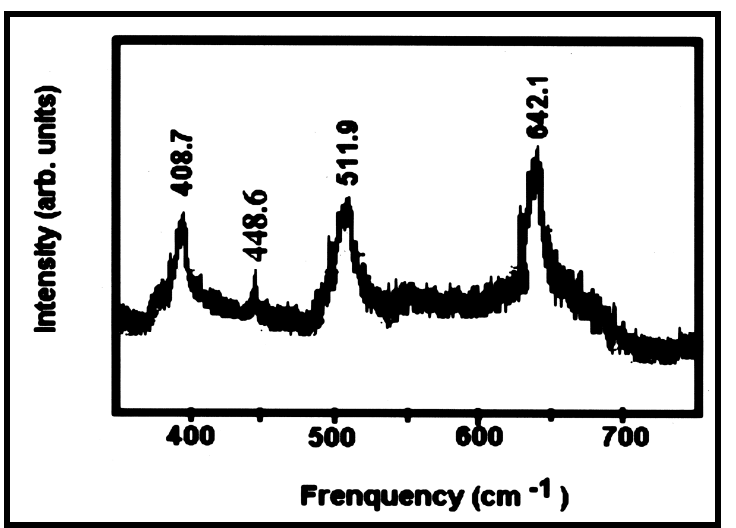

Fig 2. Raman spectrum of undoped $\mathrm{TiO}_{2}$ and $\mathrm{Mn}$-doped $\mathrm{TiO}_{2}(\mathrm{Mn}: 1,03$ at.\%).

Measurements of the photocurrent densities were made, first in dark and then under UV illumination. Fig. 3 displays the current densities obtained for the different working electrodes tested as a function of applied bias.

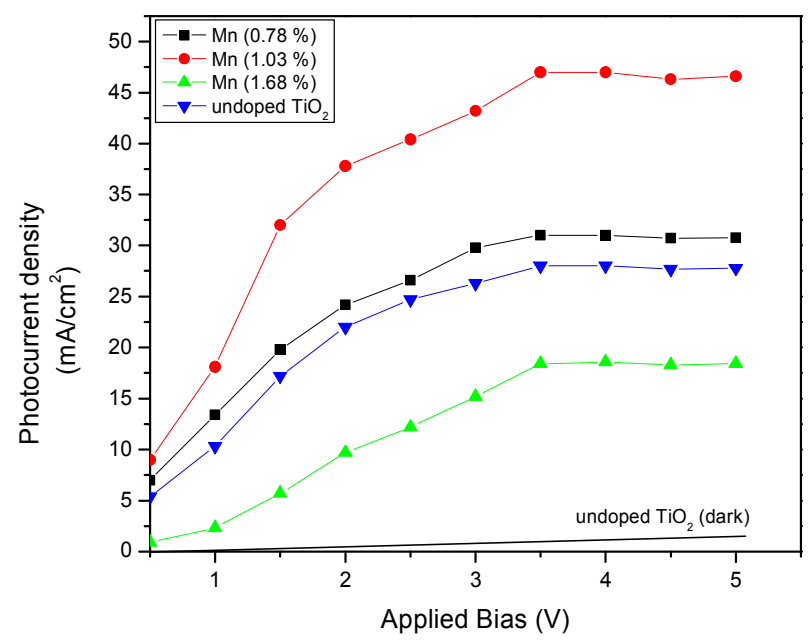

Fig 3. The current-potential curves of undoped $\mathrm{TiO}_{2}$ and $\mathrm{Mn}$-doped $\mathrm{TiO}_{2}$ electrodes (the film area: $95 \mathrm{~cm}^{2}$ illuminated by the side).

On the one hand, it can be seen from Fig. 3 that the current density increases with the applied voltage, indicating that the current density rate is much faster at high potential. Thus, it can be inferred that the $h^{+}-e^{-}$ recombination is related to the applied voltage. On the other hand, by applying the potential, electrons escape from the potential well, very likely through tunnelling. Regardless of the type of working electrode, a plateau is reached from $3.5 \mathrm{~V}$ and no significant changes in the slope of the produced photocurrent are observed. This would suggest that at this potential value, the electron tunnelling through the potential well was completed. The value of 3.5 $\mathrm{V}$ was therefore selected as the most appropriate potential bias to be applied for improving the photocatalytic properties of undoped $\mathrm{TiO}_{2}$ and of Mn-doped $\mathrm{TiO}_{2}$ semiconductors.

From Fig. 3, it can also be observed that when a potential is applied even in the presence of $\mathrm{TiO}_{2}$, yet in the dark, the electrochemical oxidation of $\mathrm{CH}_{3} \mathrm{OH}$ was not noticeable: 
the current density measured was too low, thus indicating that the oxidation of $\mathrm{CH}_{3} \mathrm{OH}$ is rather photoinduced. Consequently, it can be assumed that the complete oxidation of $\mathrm{CH}_{3} \mathrm{OH}$ that is observed was achieved essentially through photocatalysis rather than through a sole electrochemical oxidation.

The undoped $\mathrm{TiO}_{2}$ film exhibited lower current density compared to that from $\mathrm{Mn}$-doped $\mathrm{TiO}_{2}$ electrodes. This suggests that the photogenerated electron-hole pairs were separated even more efficiently in $\mathrm{Mn}$-doped $\mathrm{TiO}_{2}$ film by applying an external bias. The highest photocatalytic oxidation efficiency of $\mathrm{CH}_{3} \mathrm{OH}$ was achieved with metal doping of about $1.03 \%$ contents. This result can be rationalized by assuming that the metal in $\mathrm{TiO}_{2}$ lattice serves as shallow trapping sites and greatly enhances the activity of $\mathrm{TiO}_{2}$. It was also observed that an increase in the metal contents in $\mathrm{TiO}_{2}$ above $1.03 \%$ leads to a deterioration of the photoactivity of $\mathrm{TiO}_{2}$.

The curves in Fig.3 display the same profile as in previous works $[23,24]$. Interestingly, in our present work as well as in the latter ones, the photocurrent density reaches its highest value for a doping of around 1.00 at $\%$, regardless of the transition metal used for the doping process.

At higher manganese dopant contents, there is a sequence of decreasing average distance between the trap sites, favouring the electron-hole recombination $[25,26]$. The main role assigned to the metal in this process is shown in Eqs. 2 and 3 [27,28].

For small manganese contents and optimum number of clusters, the following sequence can be postulated:

$$
\begin{gathered}
\mathrm{TiO}_{2}\left(h_{V B}^{+} \ldots . e_{\mathrm{CB}}^{-}\right)+\mathrm{Mn} \rightarrow \mathrm{TiO}_{2}\left(h_{V B}^{+} \ldots .\right)+\mathrm{Mn}^{-} \\
\mathrm{Mn}^{-}+\mathrm{O}_{2} \rightarrow \mathrm{O}_{2}^{\cdot}+\mathrm{Mn}
\end{gathered}
$$

Manganese atoms interact with excited $\mathrm{TiO}_{2}$ to produce $\mathrm{Mn}^{-}$anions. The manganese atom $\mathrm{Mn}:[\mathrm{Ar}] \cdot 4 \mathrm{~s}^{2} \cdot 3 \mathrm{~d}^{5}$ can form a transient anion $\mathrm{Mn}^{-}:[\mathrm{Ar}] 4 \mathrm{~s}^{2} 3 \mathrm{~d}^{6}$ on addition of one electron to its electronic configuration. In the presence of dissolved oxygen, $\mathrm{O}_{2}^{\bullet}$ radicals are formed.

After production of the $O_{2}^{\bullet}$ radicals, the following steps are postulated which would lead to complete photodegradation of $\mathrm{CH}_{3} \mathrm{OH}$ into $\mathrm{CO}_{2}$ and $\mathrm{H}_{2} \mathrm{O}$ :

$$
\begin{gathered}
\mathrm{CH}_{3} \mathrm{OH}+\mathrm{O}_{2}^{\bullet} \rightarrow{ }^{\bullet} \mathrm{CH}_{2} \mathrm{OH}+\mathrm{HO}_{2}^{\bullet} \\
\mathrm{CH}_{2} \mathrm{OH}+\mathrm{O}_{2}^{\bullet} \rightarrow{ }^{\bullet} \mathrm{CHOH}+\mathrm{HO}_{2}^{\bullet} \\
\mathrm{HO}_{2}^{\bullet}+\mathrm{HO}_{2}^{\bullet} \rightarrow \mathrm{H}_{2} \mathrm{O}_{2}+\mathrm{O}_{2} \\
\mathrm{H}_{2} \mathrm{O}_{2}+\mathrm{UV} \rightarrow 2 \mathrm{HO}^{\bullet} \\
\mathrm{CH}_{3} \mathrm{OH}+\mathrm{HO}^{\bullet} \rightarrow{ }^{\bullet} \mathrm{CH}_{2} \mathrm{OH}+\mathrm{H}_{2} \mathrm{O} \\
{ }^{\bullet} \mathrm{CH}_{2} \mathrm{OH}+\mathrm{HO}^{\bullet} \rightarrow{ }^{\bullet} \mathrm{CHOH}^{\circ} \mathrm{H}_{2} \mathrm{O}
\end{gathered}
$$

$$
\text { - } \mathrm{CHOH}+\mathrm{O}_{2}^{\bullet} \rightarrow \mathrm{CO}_{2}+\mathrm{H}_{2} \mathrm{O}
$$

As can be seen, apart from the $O_{2}^{\bullet}$ radicals, a chain of other radicals (e.g. ${ }^{\bullet} \mathrm{CH}_{2} \mathrm{OH}, \mathrm{H}_{2} \mathrm{O}^{\bullet}$ and $\mathrm{HO}^{\bullet}$ ) and the hydroxycarbenes are successively produced and then involved in the oxidation of $\mathrm{CH}_{3} \mathrm{OH}$.

Additionally, from Fig. 1, it can be seen that an increase in $\mathrm{Mn}$ contents up to 2.40 at.\% leads to the formation of $\mathrm{MnO}_{2}$, while at 1.03 at.\%, only one phase of anatase $\mathrm{TiO}_{2}$ could be observed. This suggests that the decrease in the photocatalytic activity of $\mathrm{TiO}_{2}$ doped with higher metal concentration could be due to the formation of the second phase, which is rather inhibiting for the $\mathrm{TiO}_{2}$ photocatalytic activity.

From the current density measured against the applied bias as shown in Figure 3, one can suspect that the observed improvement of the $\mathrm{TiO}_{2}$ photocatalytic activity may be related to the holes generated on the surface of $\mathrm{TiO}_{2}$, which could act as potential wells. The wave nature of the electron may allow it to penetrate, by tunnelling, a thin barrier even if the electron energy is less than the height of the well.

The recombination and the reflection of an electron through a thin potential well barrier with height $V_{o}$ and width $d$ can be calculated using the corresponding Schrödinger equation in one dimension [29]. The square of the transmission coefficient $T_{0}$ is then equal to the square of the ratio of the transmitted wave $\mathrm{E}$ to the incident wave A:

$$
\begin{gathered}
T_{0}^{2}=\left|\frac{E}{A}\right|^{2}=\frac{(4 k \alpha)^{2}}{\left(\alpha^{2}+k^{2}\right)} \cdot e^{-2 \alpha d} \\
T_{0}^{2}=16 \frac{E}{V_{o}}\left(1-\frac{E}{V_{o}}\right) \cdot e^{-2 \alpha d}, \text { for } e^{2 \alpha d}>>1
\end{gathered}
$$

The transmission ( $T_{0}$ ) could be referred to as the probability of the electron to escape the hole recombination. This leads to:

$$
\begin{gathered}
T_{0}^{2}=\left|\frac{E}{A}\right|^{2}=\frac{(4 k \alpha)^{2}}{\left(\alpha^{2}+k^{2}\right)} \cdot e^{-2 \alpha d}=16 \frac{E}{V_{o}} \\
T_{o}=4 \sqrt{\frac{E}{V_{o}}} \quad \text { where } \mathrm{E}<<\mathrm{V} 0
\end{gathered}
$$

$E$ being the energy of the electron (in $\mathrm{eV}$ ), $V_{o}$ the height of the potential well (in $\mathrm{eV}$ ), and $T_{0}$ the transmission coefficient.

Moreover, the energy $E$ of the electron can be expressed by the following equation:

$$
E=F . d=\phi . e . d=\frac{U . e . d}{S}
$$


$\mathrm{F}$ is the force which makes the electron to act, $\phi$ is the electric field intensity, $e$ is the quantity of electricity, $U$ is the external potential bias expressed in volt $(\mathrm{V}), d$ is the distance separating the electron and the hole, and finally, $S$ is the distance between the anode $\left(\mathrm{TiO}_{2}\right)$ and the cathode (graphite).

By inserting Eq. 15 into Eq. 14, a parabolic Eq. 16 is obtained:

$$
T_{o}=4 \sqrt{\frac{U . e . d}{S . V_{o}}}
$$

From equation (16), one can see that the probability of the electron escaping from hole recombination increases with the potential bias that is applied. The photocurrent density which expresses the probability of reducing the recombination of the electron and the hole would then increase with the applied potential bias. The measured current densities in Fig. 3 show the same variation as that predicted by equation (16). By applying a potential of 3.5 $\mathrm{V}$, the electron can be assumed to escape by tunnelling from the well. This means that at this potential, the electron-hole recombination is best prevented, and the oxidation efficiency is consequently improved.

\section{Conclusion}

Doping with manganese improves the intrinsic photocatalytic ability of titanium dioxide as it makes possible the production of radicals which are subsequently involved in the photodegradation process. The higher photocurrent density that is observed could be the cause of the higher efficiency of $\mathrm{CH}_{3} \mathrm{OH}$ oxidation on the surface of $\mathrm{TiO}_{2}$ where the hole is acting as the oxidizing agent. The approach based on the electron tunnelling model from a well when a potential bias is applied is found to explain the experimental results in a satisfactory manner.

\section{Acknowledgements}

The authors express their thanks to Dr. Xin Lihui of the National Center of Shanghai Institute of Measurement and Testing Technology for helping with SEM, TEM, Raman and X-ray analyses.

\section{References}

[1] B. Ekoko, S. Jianian, S. XianRong, Thin Solid Films. 515 (2007) 5287-5397.

[2] D.M. Blake, Bibliography of work on the heterogeneous photocatalytic removal of hazardous compounds from water and air, in : National Technical Information Service, US Department of Commerce, Springfield, USA, Update $n^{\circ} 4$. (2001).

[3] A. Fujishima, K. Honda, Nature. 238 (1972) 37-38.

[4] R.I. Subramanian, V.M. Kuno, P.V. Kamat, J. Am. Chem.
Soc. 128 (2006) 2385-2393.

[5] J.Y. Shi, W.H. Leng, W.C. Zhu, Chem. Eng. Technol. 29 (2006) 146-154.

[6] T.A. McMurray, J.A. Byrne, P.S. Dunlop, J. Appl. Electrochem. 25 (2005) 723-731.

[7] C. Junshui, L. Meichuan, L.Z. Jidong, J. Environ. Manage. (2004) 43-47.

[8] C. He, Y. Xiong, Z. Xihai, Thin Solid Films. 422 (2002) 235-238.

[9] A. Taicheng, Z. Xihai, Y. Xiong, Mater. Phys. Mech. 4 (2001) 101-106.

[10] C.A. Morris, M.L. Anderson, R.M. Stroud, Science. 23 (1999) 622-624.

[11] A. Burns, W. Li, C. Baker, Res. Soc. Symp: Proc. 703 (2003) V.5.2.1.

[12] L. Davydov, F.P. Amaat, S.P. George, U.S. Patent, 6 (2003) 585,863 .

[13] A.M. Baraka, H.A. Hamed, H.H. Shaarawy, J. Anti-Corros. Method. Mater. 49 (2002) 282-286.

[14] I. Vrublevsky, V. Parkoun, V. Sokol, J. Schreckenbach, J. Appl. Surf. Sci. 236 (2004) 270-277.

[15] Vrublevsky, I. ; Parkoun, V. ; Schreckenbach, J. ; Max, G. J. Appl. Surf. Sci. 227 (2004) 282-292.

[16] I. Vrublevsky, V. Parkoun, V. Sokol, J. Schreckenbach, G. Max, J. Appl. Surf. Sci. 222 (2004) 215-225.

[17] J.R. Birch, T.D. Burleigh, J. Corrosion. 56 (2000) 12331241.

[18] R. Palombari, M. Ranchella, C. Rol, G.V. Sebastiani, J. Sol. Energ. Mat. Cell. 71 (2002) 359-368.

[19] J.C. Myland, K.B. Oldham, Anal. Chem. 72 (2000) 32103217.

[20] G.A. Ragoisha, A.S. Bondarenko, Electrochemistry : New research potentiodynamic electrochemical impedance spectroscopy, M. Nunez (Ed.), Nova Science Publ., New York. (2005) 51-75.

[21] T. Ohsaka, F. Izumi, Y. Fujiki, J. Raman Spectrosc. 7 (1978) 321-324.

[22] U. Balachandran, N.G. Eror, N.G., J. Solid State Chem. 42 (1982) 276-282.

[23] A. Linsbigler, C. Rusu, Y.T. Yates, J.Am.Chem.Soc. 118 (1996) 5284-5289.

[24] P.V. Kamat, J. Pure Appl. Chem. 74 (2002) 1693-1706.

[25] P.V. Kamat, J. Phys. Chem. B. 106 (2002) 7729-7744.

[26] T. Hirakawa, P.V. Kamat, J. Am. Chem. Soc. 127 (2005) 3928-3934.

[27] H. Gerischer, A. Heller, J. Phys. Chem. 95 (1991) 52615267.

[28] P.V. Kamat, Pure Appl. Chem. 74 (2002) 1693-1706. 

Manganese-Doped Titanium Dioxide

[29] S.M. Mc Murry, Quantum Mechanics, Addison-Wesley Publishing Company Inc.(1994). 